carcinoma as seen at necropsy here nor the number of histologically confirmed cases from the district has changed over the 25 years. This leaves the cases without histological confirmation. They are the weakest link in the chain. The present findings show that the postulated difference in incidence over the years lies here.

The number of cases without histological confirmation dropped from 391 in the first five years to 74 in the last. This suggests that the modern clinical diagnostic apparatus built up over these years, which is dependent on morphological confirmation, has to a great extent led to the exclusion of cases that were previously, erroneously, reported as gastric carcinoma. Changes, as shown, have occurred in the age composition of the population and, probably, in the extent to which the increased diagnostic activity has operated in the different age groups. Such discussion is beyond the scope of the present data. The major difference is between the considerable fall in the total number of cases reported and the relatively constant picture in those with histological verification. The decline in this disease reported over the past 25 years could thus well be explained on the basis of increased diagnostic accuracy.

As Barker recently pointed out, ${ }^{15}$ there is good reason to view epidemiological findings based on mortality statistics with suspicion as "the death certificate is primarily a legal document, not a record for medical research . . . the accuracy of the diagnostic data is unknown." The present findings serve to underline this warning and emphasise the need for thorough case studies in epidemiological research.
We thank the Norwegian Cancer Registry and the Central Bureau of Statistics for access to their records, and the Norwegian Cancer Society for financial support.

\section{References}

1 Doll R. Cancer in five continents. Proc $R$ Soc Lond [Biol] 1972;65:49-55. The Cancer Registry of Norway. Incidence of cancer in Norway 1972-1976. Oslo: The Norwegian Cancer Society, 1978.

3 Muir R. The alimentary tract. In: Anderson JR, ed. Textbook of pathology. 11th ed. London: Edward Arnold, 1980:603-18.

4 Morson BC. The stomach. In: Symmers WStC, ed. Systemic pathology. Edinburgh: Churchill Livingstone, 1978:1010-52.

5 Segi M, Kurihara M, Matsuyama T. Cancer mortality for selected sites in 24 countries (1964-1965). No 5, Sendai, fapan. Tohoku: Department of Public 6 The Cancer Registry of Norway. Trends in cancer incidence in Norway 1955-1967.

7 The Cancer Registry of Norway. Survival of cancer patients. Oslo: The Cance Registry of Norway, 1975 .

8 Lauren $P$. The two histological main types of gastric carcinoma: diffuse and so-called intestinal-type carcinoma. Acta Pathol Microbiol Immunol Scand $[A]$ 1965;64:31-49.

9 The Cancer Registry of Norway. Incidence of cancer in Norway 1972-1976. Oslo: The Cancer Registry of Norway, 1978 .

10 The Canadian Ministry of Health and Welfare. Chronic diseases in Canada. Quoted in UICC News $1984 ; 2: 9$.

ran ratios. F Natl Cancer Inst 1968;41:155-203.

Bjelke E. Epidemiologic studies of cancer of the stomach, colon, and rectum: 9:31-2.

Munoz N, Asvall J. Time trends of intestinal and diffuse types of gastric cancer in Norway. Int $\mathcal{F}$ Cancer $1971 ; 8: 144-57$.

14 Munoz N, Connelly R. Time trends of intestinal and diffuse types of gastric cancer in the United States. Int $\mathcal{F}$ Cancer $1971 ; 8: 158-64$. 5 Barker DJP. Time trends in cancer mortality in England and Wales. $\mathrm{Br} \mathrm{Med} \mathrm{f}$

\title{
Interval between insulin injection and eating in relation to blood glucose control in adult diabetics
}

\author{
M E J LEAN， L L NG， B R TENNISON
}

\begin{abstract}
In a survey of 225 diabetics treated with insulin $24(10 \cdot 6 \%)$ claimed never to have received advice concerning the interval between insulin injection and eating. Of the remainder, $67(33 \%)$ admitted disregarding advice and using shorter intervals. There was a significant $(p<0 \cdot 01)$ difference between the reported frequencies of clinical hypoglycaemia in patients using different intervals.

The effects on glucose control of intervals between insulin injection and breakfast of zero, 15, 30, and 45 minutes were studied for periods of one week in 11 patients with type I diabetes who were receiving twice daily injections of monocomponent porcine insulins and high fibre, high carbohydrate diets, using standard home blood glucose monitoring techniques to measure
\end{abstract}

\footnotetext{
Medical Research Council and University of Cambridge Dunn Clinical Nutrition Centre, Cambridge CB4 1 XJ

$M$ E J LEAN, MRCP, clinical scientific officer and honorary senior medical registrar
}

Addenbrooke's Hospital, Cambridge

L L NG, MRCP, medical registrar

School of Clinical Medicine, University of Cambridge, Cambridge B R TENNISON, BCHIR, PHD, clinical medical student

Correspondence to: Dr M E J Lean, Diabetic Clinic, Aberdeen Royal Infirmary, Aberdeen AB9 $1 \mathrm{GS}$. blood glucose concentrations each morning. The delay of 45 minutes resulted in the lowest frequency of hypoglycaemia and the most acceptable pattern of glucose concentrations measured one and two hours after breakfast and before lunch. Combining results obtained at these three times, the mean increment in blood glucose concentration was smaller after allowing a delay of 45 minutes than after delays of zero $(p<0.001), 15(p<0.03)$, and 30 (NS) minutes. A delay of 30 minutes resulted in smaller mean increments in blood glucose concentration than did delays of zero $(p<0.001)$ and 15 (NS) minutes.

These results suggest that this aspect of diabetic management may be neglected, with important consequences for blood glucose control. An increase in delay between insulin injection and eating to 45 minutes would be a simple and safe way of improving blood glucose control in at least the $37 \%$ of the diabetic population surveyed in this study who currently allow less than 15 minutes.

\section{Introduction}

Although the bearing of hyperglycaemia on long term problems in diabetes has been debated, ${ }^{12}$ current policy is to aim for blood glucose concentrations that are as near as possible to normal at all times. ${ }^{34}$ Diabetic patients agree with this approach, but the use of home monitoring of blood glucose concentrations has highlighted the difficulties of using conventional subcutaneous insulin regimens to control the after breakfast peak in blood 
glucose concentration ${ }^{5}{ }^{6}$ without producing hypoglycaemia around lunch time.

Improvements in control of blood glucose concentrations resulting from increasing the delay between injection of insulin and eating from five to 30 minutes, ${ }^{7}$ and up to 60 minutes when fasting blood glucose concentration is high, ${ }^{8}$ have been reported in diabetic children using subcutaneous monocomponent insulins, but these have not been previously documented in adult diabetics. The general recommendation of a delay of 30 minutes ${ }^{9}$ has been supported by studies of the rate of appearance of insulin in the circulation..$^{10-12}$ Observations on patients managed with continuous subcutaneous insulin infusion have, however, indicated that the optimum time for increasing the delivery rate is 60 minutes before eating. ${ }^{13}$ This aspect of diabetic management has not been assessed for diabetics receiving high fibre, high complex carbohydrate diets, in whom delayed nutrient absorption $^{1415}$ might permit shorter delays between subcutaneous insulin injection and eating.

The present study was designed to assess the relation of the interval between insulin injection and eating to diabetic control and, in a group of well motivated subjects, to determine the optimum interval using standard home blood glucose monitoring techniques.

\section{Patients and methods}

As part of a general screening and audit survey of all patients attending the clinics in Cambridge and Huntingdon for conversion to U-100 insulin 225 consecutive patients were studied using a short questionnaire administered by three diabetic liaison nurses. Information was collected on the clinical background of the patients, the advice they had received concerning the interval between insulin injection and eating, and the interval they actually used. They were also asked about their current frequencies, over the previous three months, of hypoglycaemia and preprandial hyperglycaemia, defined as blood glucose concentration above $10 \mathrm{mmol} / \mathrm{l}(180 \mathrm{mg} / 100 \mathrm{ml})$ or urine tests showing $2 \%$ glycosuria. The nursing staff were aware of the aims of the questionnaire but had been warned not to prompt patients in such a way as to bias responses. Blood was taken at the same visit for measurement of glycosylated haemoglobin $\left(\mathrm{HbA}_{1}\right)$, if this had not been done in the previous six months, using a kit method based on the method of Schnek and Schroeder ${ }^{16}$ (Test-Combination Hemoglobin Al ; Boehringer).

Six healthy men and six healthy women with type I diabetes were selected for further study (timing study). A pilot study had shown a within subject standard deviation of postprandial increase in blood glucose concentration of the order of $3 \mathrm{mmol} / 1(54 \mathrm{mg} / 100 \mathrm{ml})$. The sample size of 12 was therefore chosen to give the experiment a power of at least $80^{\circ}$ of detecting, at the $5^{\circ}{ }_{\circ}$ significance level, a difference of $2 \mathrm{mmol} / 1(36 \mathrm{mg} / 100 \mathrm{ml})$ in the blood glucose concentration at any time. All subjects were regular attenders at the clinic and had at least one year's experience of regular home blood glucose monitoring. All were considered to be reliable by medical, nursing, and dietetic staff, and thought to be in a stable state of reasonable diabetic control. All were managed with twice daily subcutaneous injections of combined rapid and intermediate acting monocomponent porcine insulins in concentrations of 40 or $80 \mathrm{U} / \mathrm{ml}$ and an energy regulated diet containing $50-55^{\circ}{ }_{0}$ of total energy as carbohydrates, high in dietary fibre, $30-35^{\circ}{ }_{0}$ as fats, low in saturated fats. One woman dropped out of the study after one week owing to a change in insulin dose. Table I shows the clinical details of the remaining 11 subjects.

TABLE I-Clinical details of 11 subjects participating in timing study

\begin{tabular}{lc}
\hline & Mean (range) data \\
\hline Age (years) & $44(18-56)$ \\
Duration of diabetes (years) & $11(1-29)$ \\
Body mass index (kg/m²) & $23 \cdot 6(20 \cdot 4-27 \cdot 6)$ \\
Total daily insulin dose (units) & $76(24-68)$ \\
Mean fasting blood glucose during study (mmol $/ 1)$ & $9 \cdot 0(4 \cdot 1-10 \cdot 5)$ \\
Glycosylated haemoglobin $\left({ }^{\circ}\right)^{*}$ & $9 \cdot 7 \cdot 12 \cdot 6)$ \\
\hline
\end{tabular}

Conversion: SI to traditional units-Glucose: $1 \mathrm{mmol} / 1 \approx 18 \mathrm{mg} / 100 \mathrm{ml}$
The study lasted four weeks, during which time subjects were asked to continue their normal diet and regular daily activities at home or a work. Insulin dose was not altered, only the thighs were used for injections, and no drugs other than insulin were taken. The intervals studied between injection and eating were zero, 15, 30, and 45 minutes. For each week each subject used one of these intervals both morning and evening. The orders in which the intervals were used were allocated between subjects according to a design based on Latin squares, to eliminate order effects.

Samples of capillary blood were taken with an Autolet (Owen Mumford) and measured with the Dextrostix-Glucometer system (Ames) at five different times each morning: immediately before injection; immediately before breakfast; one hour after breakfast two hours after breakfast (before mid-morning snack); immediately before lunch. C peptide was measured by radioimmunoassay kit (IRE CPEP RIA100) with a lower limit of detection of $0.1 \mathrm{nmol} / 1$

Hypoglycaemic reactions at any time of day were recorded. The meters were calibrated at the beginning of each week, and the perspex windows were cleaned regularly. Subjects were instructed to be particularly careful about precise time keeping.

TABLE II-Clinical details of 225 patients studied by questionnaire

\begin{tabular}{lc}
\hline & Clinical findings \\
\hline No (o o) of women & $106(48)$ \\
Mean (range) age, in years & $45(17-82)$ \\
Mean (range) years since diagnosis & $14 \cdot 7(0 \cdot 2-52)$ \\
Mean (range) years receiving insulin & $12 \cdot 5(0 \cdot 2-46)$ \\
No (oo) taking: & \\
Insulin twice daily or more & $194(86 \cdot 2)$ \\
Insulin once daily & $31(13 \cdot 8)$ \\
Monocomponent insulins & $169(75 \cdot 1)$ \\
Conventional insulins & $56(24 \cdot 9)$ \\
No (oo) with: & $107(47 \cdot 5)$ \\
Blood tests reported & $106(47)$ \\
Urine tests reported & $12(5 \cdot 3)$ \\
No testing reported & \\
\hline
\end{tabular}

TABLE III-Number $(\%)$ of patients in a group of 225 advised to allow a certain interval between insulin injection and eating and number $(\%)$ actually doing so. (Twenty four patients $(10 \cdot 7 \%)$ claimed to have received no advice on this subject)

\begin{tabular}{lcc}
\hline $\begin{array}{l}\text { Duration of interval } \\
\text { (min) }\end{array}$ & $\begin{array}{c}\text { No }\left(0_{0}\right) \\
\text { advised }\end{array}$ & $\begin{array}{c}\text { Actual No } \\
\left({ }_{0}^{0}\right)\end{array}$ \\
\hline $0-10$ & $9(4)$ & $41(18 \cdot 2)$ \\
$11-20$ & $61(27 \cdot 1)$ & $98(43 \cdot 6)$ \\
$21-30$ & $128(56 \cdot 9)$ & $79(35 \cdot 1)$ \\
$>30$ & $3(1 \cdot 3)$ & $7(3 \cdot 1)$ \\
\hline
\end{tabular}

\section{STATISTICAL ANALYSES}

The results of the questionnaire concerning frequency of hypoglycaemia and hyperglycaemia appeared not to be normally distributed. A Kruskal-Wallis analysis of variance was used to compare these frequencies in three groups of subjects-namely, those whose interval between injection and eating was less than 15 minutes, those whose interval was between 15 and 30 minutes, and those whose interval was at least 30 minutes.

In the timing study the fasting blood glucose concentration was taken to be the mean of the values before injection and before eating and the increments in blood glucose concentrations above fasting concentrations were studied using two way analysis of variance to compare the four injection regimens while eliminating differences between subjects. If a result were missing, to be able to use analysis of variance, the expected increment was computed as the mean of increments on other days of that week in the same subject, with a consequent reduction of one degree of freedom. ${ }^{17}$ If more than three computed results were required to make up the seven days the results from that subject were excluded from the analysis for that interval. Computed results were not included in the calculation of the mean increase in blood glucose concentration (see table VI).

Results are quoted as mean (SEM) unless otherwise stated, and the level of significance was taken as $p<0.05$. In the analysis of results from the timing study levels of significance are quoted only when an $F$ test showed a significant difference between the treatment effects. 
TABLE IV-Mean (SD) frequencies of clinical hypoglycaemia and hyperglycaemia reported by 225 diabetics receiving insulin according to interval between insulin injection and eating

\begin{tabular}{lccc}
\hline $\begin{array}{l}\text { Duration of } \\
\text { interval (min) }\end{array}$ & $\begin{array}{c}\text { No of } \\
\text { patients }\end{array}$ & $\begin{array}{c}\text { Clinical hypoglycaemia } \\
\text { (episodes/month) }\end{array}$ & $\begin{array}{c}\text { Hyperglycaemia } \\
\text { ("o of preprandial tests) }\end{array}$ \\
\hline$<15$ & 67 & $1 \cdot 51(1 \cdot 82)$ & $14 \cdot 0(19 \cdot 8)$ \\
$15-29$ & 82 & $1 \cdot 17(2.57)$ & $6 \cdot 0(11 \cdot 8)$ \\
$\geqslant 30$ & 76 & $1 \cdot 46(2 \cdot 38)$ & $7 \cdot 4(15 \cdot 6)$ \\
\hline Kruskal-Wallis $x^{2 *}$ & $9 \cdot 72(\mathrm{p}<0 \cdot 01)$ & $5 \cdot 35(\mathrm{p}<0 \cdot 1)$ \\
\hline
\end{tabular}

*Percentage points of $\chi^{2}$ are $4.61(p<0.1), 5.99(p<0.05)$, and $9.21(p<0.01)$.
The patients who used longer intervals than they had been advised did so because they found it improved their control.

Table IV shows a summary of data on the reported frequencies of hypoglycaemia and hyperglycaemia. The Kruskal-Wallis analysis of variance showed a significant difference between the three groups in frequency of hypoglycaemia $(p<0.01)$ but a non-significant difference in frequency of hyperglycaemia $(p<0 \cdot 1)$. The nature of the difference was further investigated by the timing study.

Mean glycosylated haemoglobin in patients using intervals of 10 minutes or less was $9.0(1.4) \%(n=21)$ and in patients using intervals of 30 minutes $9.7(1.9) \%(n=31)$. The difference between these figures was not significant.

\section{TIMING STUDY}

The zero minutes' delay was stopped after four subjects had used it for a week as the results were clearly worse. The experimental design permitted this while maintaining a balanced ordering of timing intervals. Excluding results obtained after treatment for clinical hypoglycaemia or unusual activity, there were 189 measurements of blood glucose concentration for analysis from the 11 subjects for one hour after breakfast, 174 for two hours after breakfast, and 187 for before lunch (out of a possible maximum of 231 measurements each).

TABLE VI-Mean (SEM) effects on glucose control of intervals of zero, 15, 30, and 45 minutes between insulin injection and eating from two way analysis of variance of increments in blood glucose concentration above mean fasting value, measured at one hour after breakfast, two hours after breakfast, and before lunch, and the mean of these three increments

\begin{tabular}{|c|c|c|c|c|}
\hline \multirow{2}{*}{$\begin{array}{l}\text { Duration of } \\
\text { interval (min) }\end{array}$} & \multicolumn{3}{|c|}{ Increments in blood glucose $(\mathrm{mmol} / \mathrm{l})$} & \multirow{2}{*}{$\begin{array}{l}\text { Overall mean } \\
\text { increment }(\mathrm{mmol} / \mathrm{l})\end{array}$} \\
\hline & 1 hour after breakfast & 2 hours after breakfast & Before lunch & \\
\hline $\begin{array}{r}0 \\
15 \\
30 \\
45\end{array}$ & $\begin{array}{l}9.35(0.54)^{* * * *} \\
4.87(0.46) \\
3.51(0.46) \\
4.51(0.46)\end{array}$ & $\begin{array}{l}8.36(0.65)^{* * * *} \\
1.83(0.47)^{*} \\
1.88(0.47)^{*} \\
0.56(0.47)\end{array}$ & $\begin{aligned} & 2.85(0.70)^{* * * *} \\
-1.44(0.56) & -1.73(0.56) \\
- & 1.43(0.56)\end{aligned}$ & $\begin{array}{l}7.29(0.65)^{* * * *+} \\
1.57(0.41)^{* *} \\
1.00(0.41) \\
0.46(0.41)\end{array}$ \\
\hline
\end{tabular}

Significance of difference of comparison with 45 minute interval; ${ }^{*} \mathrm{p}<0.05 ;{ }^{* *} \mathrm{p}<0.03 ;{ }^{* * *} \mathrm{p}<0.01 ;{ }^{* * * *} \mathrm{p}$ Significa
0.001

tp 0.001 in comparison with 30 minute interval.

Conversion: SI to traditional units-Glucose: $1 \mathrm{mmol} / 1 \approx 18 \mathrm{mg} / 100 \mathrm{ml}$.

For each table entry the number of degrees of freedom was at least 50 . The multipliers to be applied to the SEM

to obtain $95 \%$ and $99 \%$ confidence limits using $\mathrm{t}_{50}$ are 2.01 and 2.68 respectively. Levels of significance are quoted only where an F test showed a significant difference between the treatment
effects.

TABLE VII-Mean (SEM) increase in blood glucose above fasting concentrations calculated from measure ments one hour after breakfast, two hours after breakfast, and before lunch and allowing intervals of zero, 15, 30, and 45 minutes between insulin injection and breakfast

\begin{tabular}{lc}
\hline $\begin{array}{l}\text { Duration of interval } \\
(\mathrm{min})\end{array}$ & $\begin{array}{c}\text { Overall mean increase } \\
\text { in blood glucose }(\mathrm{mmol} / \mathrm{l})\end{array}$ \\
\hline 0 & $7 \cdot 3^{* * *}$ \\
15 & $1 \cdot 6^{*}$ \\
30 & 0.0 \\
45 & 0.5 \\
\hline
\end{tabular}

Conversion: SI to traditional units-Glucose: $1 \mathrm{mmol} /$ Conversion: $S I$
$\approx 18 \mathrm{mg} / 100 \mathrm{ml}$ $\approx \mathrm{p}<0.03$ in comparison with 45 minute interval. ** $<0.001$ in comparison with 30 and 45 minute intervals.

\section{Results}

\section{QUESTIONNAIRE}

Table II gives clinical details of the 225 patients studied. Twenty four $(10 \cdot 7 \%)$ claimed never to have received specific advice about the interval between insulin injection and eating. Of the remaining 201 patients who recalled being given advice, only $126(58 \%)$ said that they had been advised to delay for more than 20 minutes (table III). The intervals actually used were even shorter, with $67(33 \%)$ of patients using intervals shorter than advised, $121(60 \%)$ using their advised interval, and $13(6 \%)$ using intervals longer than advised. The reasons given for reducing the delay were convenience and fear of hypoglycaemic reactions in the intervals before eating.
The fall in blood glucose concentration between insulin injection and breakfast with an interval of 45 minutes was $0.03(0.18) \mathrm{mmol} / 1$ $(0.54(3.24) \mathrm{mg} / 100 \mathrm{ml})$. No clinical hypoglycaemia developed during this interval after either morning or evening injections. The mean fasting blood glucose concentration for each week was not affected by the interval being used (table V).

The frequencies of clinical hypoglycaemia per subject, at any time of day, in the weeks using each interval were as follows: 0.87 with an interval of zero minutes; 1.14 with 15 minutes; 0.81 with 30 minutes; and 0.54 with 45 minutes. There were no significant differences between these figures.

Table VI shows the increments in blood glucose concentration above mean fasting concentrations at the three times. Analysis of the means of the blood glucose concentrations at the three times shows (tables VI and VII) that, although the delay of 45 minutes did not produce results significantly different from the delay of 30 minutes, it did produce results significantly different from the delay of 15 minutes $(\mathrm{p}<0.03)$.

Subjects in whom tests for $C$ peptide were negative $(n=7)$ were analysed separately. They did not show different overall effects from the different intervals.

\section{Discussion}

The rate of absorption of subcutaneously injected insulin depends on many factors including: the formulations and mixing of different insulins and the length of delay between mixing and injecting ${ }^{10-1218}$; the site $^{10-12}$ and depth of injection ${ }^{19}$; and the state of local vasculature related to temperature, ${ }^{20}$ exercise, ${ }^{21}{ }^{22}$ and smoking. ${ }^{23}$ The presence of local proteolytic enzymes 
causing subcutaneous insulin degradation ${ }^{24} 25$ and circulating anti-insulin antibodies ${ }^{26}$ may affect the onset of action of injected insulin. The optimum interval between insulin injection and eating will also depend on the rate of absorption of nutrients.

Studies on insulin dependent diabetics using an artificial pancreas have shown that after a mixed meal there is a delay of 11-19 minutes before an increase in blood glucose concentration is detected. ${ }^{15}$ This may be further delayed by autonomic neuropathy causing gastric stasis ${ }^{27}$ and is affected by the form of food ingested. The mechanism of action of dietary fibre, particularly viscous fibre, in flattening blood glucose responses is complex, but delayed nutrient absorption certainly plays a part. ${ }^{14}{ }^{15} \mathrm{High}$ fibre diets reduce total insulin requirements in diabetics ${ }^{28}$; on theoretical grounds this may be partly through improved matching of subcutaneous insulin activity with postprandial rise in blood glucose concentration. All the findings in this study relate to patients attending clinics where the high fibre, high complex carbohydrate diet has been standard teaching for three years.

Although a 30 minute delay is currently recommended, the results of the questionnaire survey show that advice to the diabetic population regarding the interval between insulin injection and eating has been mixed and is often ignored or adapted by patients.

The observation of a significant difference in the frequency of hypoglycaemia between subjects using different intervals suggests that this factor might contribute significantly to poor overall control. At first sight the lack of difference in glycosylated haemoglobin between groups of patients using short and long intervals argues against this, but fluctuations in blood glucose concentration towards hypoglycaemia and hyperglycaemia occurring in the same patient can have opposite and cancelling effects on glycosylated haemoglobin. ${ }^{29}$ In this situation glycosylated haemoglobin may be misleading as an index of overall control, by concealing rapid fluctuations in blood glucose concentration that have been related to the development of long term complications. ${ }^{1}$

Home blood glucose monitoring has been strongly advocated as a means of improving control of blood glucose concentrations. ${ }^{40}$ With good patient education and perhaps quality control checking ${ }^{31}$ excellent correlations can be achieved between the Glucometer system used in this study and laboratory analysis of blood glucose. ${ }^{32}{ }^{33}$ Home blood glucose monitoring has not been widely used in studies of diabetic control, though it has attractive advantages for certain studies (acceptability to patients, large numbers of observations possible, low cost compared with hospital based studies, and freedom from disruption of normal home or working routines). In the present study each subject was asked to make five timed measurements a day for 21 days (or 28 days for the four subjects who tested the zero minutes' delay). Of the 1120 tests requested, 997 measurements were returned, a compliance of $89 \%$.

This study confirmed for adult patients the finding of Kinmonth and Baum that a 30 minute interval results in better diabetic control than injection immediately before eating, ${ }^{7}$ and there was further improvement with a delay of 45 minutes, which produced significantly better results than a delay of 15 minutes. Although this study did not show a delay of 45 minutes to be significantly better than one of 30 minutes in terms of frequency of hypoglycaemia and hyperglycaemia assessed individually, other patients subject to rapid swings in blood glucose concentration during the morning anecdotally reported improved stability with intervals longer than the 30 minutes generally recommended. All the patients studied, and the subjects in the timing study, were using porcine or bovine insulins in strengths of 40 or $80 \mathrm{U} / \mathrm{ml}$. U-100 insulin $(100 \mathrm{U} / \mathrm{ml})$ has been found to have a slower absorption rate from subcutaneous injection, ${ }^{12}{ }^{19}$ so it is possible that the changeover to U-100 insulin will further worsen diabetic control in those using short intervals between injection and eating. More rapidly absorbed insulin preparations would be of benefit.

The longer intervals are generally considered to be inconvenient, but the reorganisation required is not great, ? and the fear of hypoglycaemia during the increased delay is unfounded. Increasing the interval between insulin injection and eating to 45 minutes would significantly improve control for at least those patients who currently delay 15 minutes or less. This amounted to $37 \%$ (83) of the population in our survey. Advice on this aspect of management clearly needs to be reinforced in the diabetic population.

We thank Joan Bendall, Kate Stafford-Sheath, and Norah Heard for their help in patient education and completing the questionnaires; Dr T M Chalmers and Dr O M Edwards for permission to study patients under their care; and Bill Jervis, Ames Division, Miles Laboratories, for the gift. of glucometers for research purposes.

\section{References}

1 Tchobroutsky G. Relation of diabetic control to development of microvascula complications. Diabetologia 1978;15:143-52.

2 Siperstein MD, Foster DW, Knowles HC, Levine R, Madison LL, Roth J. Control of blood glucose and diabetic vascular disease. $N$ Engl $\mathcal{F}$ Med 1977 ;

West KM. Hyperglycaemia as a cause of long term complications. In: Keen $\mathrm{H}$, Jarrett RJ, eds. The complications of diabetes. London: Edward Arnold, 1982:

4 Tattersall RB. Home blood glucose monitoring. Diabetologia 1979;16:71-4. profiles in diabetic children receiving insulin injections once or twice daily. Br Med F 1980;281:414-8.

6 Phillips M, Simpson RW, Holman RR, Turner RC. A simple and rational twice daily insulin regime. $Q \mathcal{F}$ Med 1979;191:493-506.

7 Kinmonth AL, Baum JD. Timing of pre-breakfast insulin injection and postprandial metabolic control in children. Br Med 7 1980;280:604-6

MF, White NH, Santiago JV. Role of site and timing of insulin injections in diabetic children (IDD's). Diabetes 1982;31 (suppl 2):52A

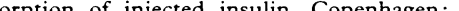
Thesis. Berger M, Cuppers HJ, Hegner H, Jorgens V, Berchtold P. Absorption kinetics and biologic effects of subcutaneously injected insulin preparations. Diabetes

12 Galloway JA, Spradlin CT, Nelson RL, Wentworth SM, Davidson JA, Swarner $\mathrm{JL}$. Factors influencing the absorption, serum insulin concentrations, and blood glucose responses after injections of regular insulin and various insulin mixtures. Diabetes Care 1981;4:366-76.

13 Dimitriadis GD, Gerich JE. Importance of timing of preprandial subcutaneous (n)

14 Jenkins DJA, Wolever TMS, Leeds AR, et al. Dietary fibres, fibre analogues and glucose tolerance: importance of viscosity. $\mathrm{Br}$ Med $\mathcal{F}$ 1978; ; :1392-4.

15 Slama G, Klein J-C, Delage A, et al. Correlation between the nature and amoun of carbohydrate in meal intake and insulin delivery by the artificial pancreas in 24 insulin-dependent diabetics. Diabetes $1981 ; 30: 101-5$.

16 Schnek AG, Schroeder WA. The relation between the minor components whole normal human adult hemoglobin as isolated by chromatography and starch block 83:1472-8.

7 Armitage P. Statistical methods in medical research. Oxford: Blackwell, $1971: 260$. rootendorst BC, Jonkers JR, Kruit I. The miscibility of short acting insulin with depot insulins. An in vitro study. Pharm Weekbl 1983;118:746-51. short-acting soluble insulin: influence of injection technique and concentration. Diabetes Care 1983;6:459-62.

20 Koivisto VA, Fortney S, Hendler R, Felig P. A rise in ambient temperature augments insulin absorption in diabetic patients. Metabolism 1981;30:402-5. action in diabetics. Br Med $\mathscr{f}$ $1926 ; \mathrm{i}: 648-50$

22 Koivisto VA, Felig P. Effects of leg exercise on insulin absorption in diabetic patients. $N$ Engl 7 Med 1978;298:79-83.

lemp P, Staberg B, Madsbad S, Kolendorf K. Smoking reduces insulin absorpBerger M, Halban PA, Girardier L, Seydoux J, Offord RE, Renold AE. Absorption kinetics of subcutaneously injected insulin. Evidence for degradation at the injection site. Diabetologia 1979;17:97-100.

25 Stevenson RW, Tsakok TI, Parsons JA. Matched glucose responses to insulin administered subcutaneously and intravenously. Evidence for subcutaneous inativation of insulin. Diabetologia 1980;18:423-6.

26 Reeves WG, Kelly U. Insulin antibodies produced by bovine insulin therapy. Clin Exp Immunol 1982:50:163-70.

27 Campbell A, Conway H. Gastric retention and hypoglycaemia in diabetes. $S$ cott Med 7 1960;5:167-8. 28 Anderson JW, Midgley WR, Wedman B. Fiber and diabetes. Diabetes Care

29 Gale EAM, Walford S, Tattersall RB. Nocturnal hypoglycaemia and haemoglobin A1. Lancet 1979 ;ii: 1240

30 Walford S, Gale EAM, Allison SP, Tattersall RB. Self-monitoring of blood glucose. Improvement of diabetic control. Lancet 1978 ; i :732-5.

1 Petranyi G, Petranyi M, Scobie IN, et al. Quality control of home monitoring of blood glucose concentrations. Br Med $\mathcal{f} 1984 ; 288: 757$.

2 Schiffrin A, Desrosiers M, Belmonte M. Evaluation of two methods of self blood

glucose monitoring by trained insulin-dependent diabetic adolescents outside
the hospital. Diabetes Care 1983;6:166-9.
33 Drucker RF, Williams DRR, Price CP. Quality assessment of blood glucose monitors in use outside the laboratory. $f$ Clin Pathol 1983;36:948-53.

(Accepted 2 October 1984) , 象 咅 年 . 을 然

\section{N}

